\title{
Study on drug usage pattern of anxiolytics in psychiatric department in a tertiary care teaching hospital at Dehradun, Uttarakhand, India
}

\author{
Shakti B. Dutta ${ }^{1}$, Mirza A. Beg*1, Shalu Bawa ${ }^{1}$, Amanjot Kaur ${ }^{1}$, \\ Subhash Vishal ${ }^{1}$, Nand Kishore Singh ${ }^{2}$
}

${ }^{1}$ Department of Pharmacology, ${ }^{2}$ Department of Psychiatry, Shri Guru Ram Rai Institute of Medical and Health Sciences, Patel Nagar, Dehradun, Uttarakhand, India

Received: 18 April 2017

Revised: 24 April 2017

Accepted: 16 May 2017

*Correspondence to:

Dr. Mirza A. Beg,

Email: mabeg1997@gmail.com

Copyright: (c) the author(s), publisher and licensee Medip Academy. This is an openaccess article distributed under the terms of the Creative Commons Attribution NonCommercial License, which permits unrestricted noncommercial use, distribution, and reproduction in any medium, provided the original work is properly cited.

\begin{abstract}
Background: Psychopharmacology is a rapidly growing field, in which the number of patients is continuously increasing. Newly introduced drugs are projected as the better alternative to the traditional psychiatric medicines. The utilization and consequences on real life effectiveness and safety of antianxiety drugs in actual clinical practice need continuous monitoring. Aim of the present study was to analyze the pattern of various anxiolytic drugs prescribed to the patients in psychiatric department of a tertiary care teaching hospital.
\end{abstract}

Methods: The present study was conducted by the department of pharmacology, in the department of psychiatry at SGRRIM and HS, Dehradun, for a period of 6 months from June 2016 to December 2016. Prescriptions of patients diagnosed with anxiety were analysed, using WHO drug use indicators. Results: A total of 603 prescriptions with anxiety disorder were collected. The mean age was $35.46 \pm 0.88$ years. Majority of the patients were in 31-50 years age group $309(51.24 \%)$. Male:Female ratio was 1:0.69. Disease pattern observed during the study were $177(29.35 \%)$ generalized anxiety disorder, 147 (24.38\%) depression, 99 (16.42\%) obsessive compulsive disorder (OCD), 81 (13.43\%) psychotic illness, $63(10.45 \%)$ bipolar disorders and $36(5.97 \%)$ patients categorized as others category respectively. A total of 1974 psychotropic drugs were prescribed, $654(33.13 \%)$ antianxiety drugs, 648 $(32.83 \%)$ antidepressants, $240(12.16 \%)$ antipsychotics, $198 \quad(10.03 \%)$ antiepileptics and $234(11.85 \%)$ miscellaneous drugs were prescribed. 552 $(91.54 \%)$ patients received monotherapy and $51(8.46 \%)$ were given polytherapy of anxiolytics. All $(100 \%)$ anxiolytics were orally prescribed. A total of 30 fixed dose combinations (FDCs) of anxiolytics were prescribed. The numbers of anxiolytics per prescription were 1.085. The anxiolytics prescribed from National Essential Medicine List 2015 were 555 (84.86\%). The percentage of anxiolytics with brand names were 618 (94.5\%).

Conclusions: Most of the prescriptions were rational but there is a need to encourage prescribing by generic names so that more cost-effective and rational treatment can be provided to the patients.

Keywords: Anxiolytics, Drug utilization, Psychopharmacology, Rational prescribing

\section{INTRODUCTION}

Anxiety disorders are a group of conditions in which the feelings of anxiety are not associated with a real or appropriate threat, or are much more intense and long lasting than they should be. People feel frightened and distressed for no apparent reason. Anxiety disorders are common - nearly $25 \%$ of people experience anxiety disorders at some time in their lives. The simultaneous occurrence of depression and anxiety is very common. The combination is well recognized and can significantly increase the disability and disruption of normal function suffered by the patient. The anxiety associated with depression can take many forms including panic attacks, obsessive compulsive disorder, post-traumatic stress disorder, social anxiety disorder or a generalized anxiety 
disorder. ${ }^{1}$ An anxiolytic is a drug used for the treatment of anxiety, and its related psychological and physical symptoms. ${ }^{2}$ Anxiolytics have been shown to be useful in the treatment of anxiety disorders. The preferred medications for most anxiety disorders are the benzodiazepines. ${ }^{3}$ In addition to the benzodiazepines, a non-benzodiazepine, buspirone, is used for generalized anxiety disorders. ${ }^{2}$ Beta-receptor blockers such as propranolol and oxprenolol, although not anxiolytics, can be used to combat the somatic symptoms of anxiety. ${ }^{2}$

The World Health Organization (WHO) defined drug utilization as the marketing, distribution, prescription and use of drugs in a society, considering its consequences, medical, social, and economic. ${ }^{4}$ Drug utilization pattern in both in and out patients departments of various teaching care hospital and medical care providing institutions must need a proper intermittent and judicious monitoring to minimize irrational practice of drug prescription, to analyze the rationality of every prescription, to offer suitable modifications in prescribing pattern to increase the therapeutic benefits and reduce adverse effects. Data of drug usage pattern at out-patient and inpatient departments of tertiary care teaching hospitals and analysis of that data is a very beneficial measure to formulate guidelines for improving the pattern of prescriptions aligned to rationality and effective outcome of the treatment with cost effectiveness. Psychopharmacology is a rapidly growing field, in which the number of patients are continuously increasing and lots of newly introduced drugs are coming into the market to which psychiatrists are very much exposed now a days that are claimed and projected as the better alternative to the existing/older psychiatric medicines by the pharmaceutical companies. ${ }^{5}$ Although psychotropic medications have had a remarkable impact on psychiatric practice that legitimately can be called revolutionary, their utilization and consequences on real life effectiveness and safety in actual clinical practice need continuous study. ${ }^{6}$ The data on usage of anxiolytics is lacking. In view of this, the present study was designed to analyze the drug utilization pattern of antianxiety drugs in Psychiatry Department of a tertiary care hospital.

\section{METHODS}

This prospective study was conducted by department of pharmacology in outpatient department of psychiatry at Shri Guru Ram Rai Institute of medical and health sciences (SGRRIM and HS), Dehradun, for a period of 6 months from June 2016 to December 2016.

A total of 603 prescriptions of patients diagnosed with anxiety disorder were collected from Psychiatry Outpatients Department. Prior to the initiation of the study, approval of the institutional ethics committee was obtained. Prescription of patients diagnosed with anxiety was analysed. Only complete prescriptions containing anxiety history and treatment details were included in the study. The following WHO drug use indicators were determined: Average number of drugs per prescription, dosage form of drugs, number of fixed dose combinations (FDCs) prescribed, the number of the drugs prescribed with generic or proprietary name(s), the number of drugs prescribed from essential medicine list (EML) 2015.

\section{RESULTS}

A total of 603 prescriptions of patients diagnosed with anxiety disorder were collected from psychiatry department. The mean age of the patients was $35.46 \pm 0.88$ years. Age wise distribution of patients was done. Majority of patients 309 (51.24\%) were in 31-50 years of age group followed by $210(34.82 \%)$ in $18-30$ years, 63 $(10.45 \%)$ in $>50$ years and $21(3.48 \%)$ in $<18$ years of age group. Male:Female ratio was 1:0.69. The patients were distributed according to their professions, 213 (35.32\%) housewives, $126(20.89 \%)$ self- employed, 99 (16.41\%) students, 93 (15.42\%) Private Job, 42 (6.96\%) Government Job and $30(4.97 \%)$ were categorized as others respectively. $486(80.60 \%)$ patients belong to middle class, $108(17.91 \%)$ were from lower class and 9 (1.49\%) belongs to upper class. 324 (53.73\%) were vegetarians and $279(46.27 \%)$ were non-vegetarians. 258 $(42.78 \%)$ patients had a positive addiction history, smoking 144 (23.88\%), alcohol $93(15.42 \%)$ and drug abuse $21(3.48 \%)$ respectively (Table 1$)$.

Table 1: Demographic profile.

\begin{tabular}{|c|c|c|}
\hline Parameter & Groups & Number $(\%)$ \\
\hline Male: Female & $357: 246(1: 0.69)$ & \\
\hline Mean Age (in years) & $35.465 \pm 0.88$ & \\
\hline \multirow{4}{*}{$\begin{array}{l}\text { Age (in years) } \\
\text { distribution }\end{array}$} & $<18$ & $21(3.48 \%)$ \\
\hline & $18-30$ & $210(34.82 \%)$ \\
\hline & $31-50$ & $309(51.24 \%)$ \\
\hline & $>50$ & $63(10.45 \%)$ \\
\hline \multirow{6}{*}{ Profession } & Housewife & $213(35.32 \%)$ \\
\hline & Self employed & $126(20.89 \%)$ \\
\hline & Student & $99(16.41 \%)$ \\
\hline & Private Job & $93(15.42 \%)$ \\
\hline & Govt. Job & $42(6.96 \%)$ \\
\hline & Others & $30(4.97 \%)$ \\
\hline \multirow{3}{*}{$\begin{array}{l}\text { Socioeconomic } \\
\text { status }\end{array}$} & Middle class & $486(80.60 \%)$ \\
\hline & Lower class & $108(17.91 \%)$ \\
\hline & Upper class & $9(1.49 \%)$ \\
\hline \multirow{2}{*}{ Dietary habits } & Vegetarian & $324(53.73 \%)$ \\
\hline & Non-vegetarian & $279(46.27 \%)$ \\
\hline \multirow{3}{*}{ Addiction } & Smoking & $144(23.88 \%)$ \\
\hline & Alcohol & $93(15.42 \%)$ \\
\hline & Drugs & $21(3.48 \%)$ \\
\hline
\end{tabular}

The disease pattern of patients was analyzed, 177 $(29.35 \%)$ generalized anxiety disorder, 147 (24.38\%) depression, $99(16.42 \%)$ obsessive compulsive disorder (OCD), 81 (13.43\%) psychotic illness, 63 (10.45\%) bipolar disorders and $36(5.97 \%)$ patients belonged to others category respectively (Figure 1). 


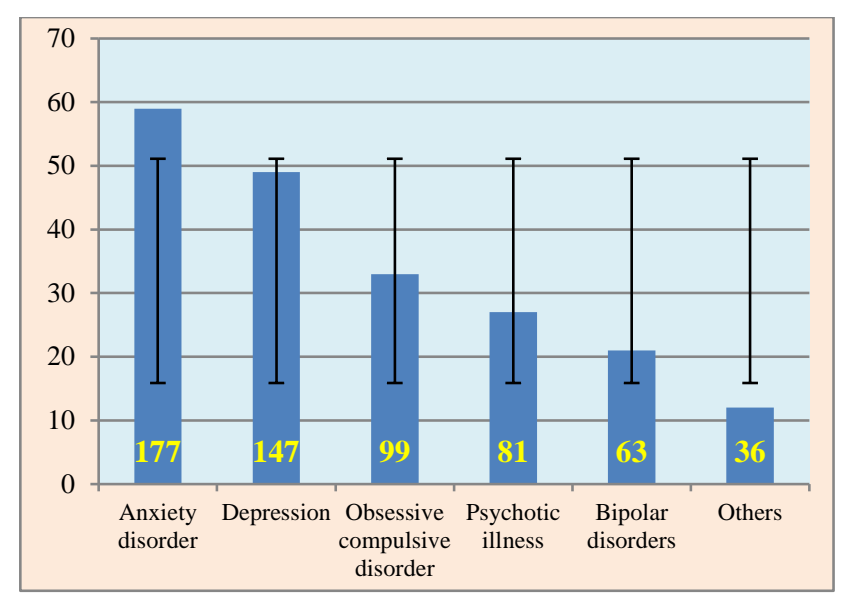

Figure 1: Disease pattern.

A total of 1974 psychotropic drugs were prescribed, 654 $(33.13 \%)$ antianxiety drugs, $648 \quad(32.83 \%)$ antidepressants, $240(12.16 \%)$ antipsychotics, 198 $(10.03 \%)$ antiepileptics and $234(11.85 \%)$ miscellaneous drugs were prescribed respectively (Figure 2).

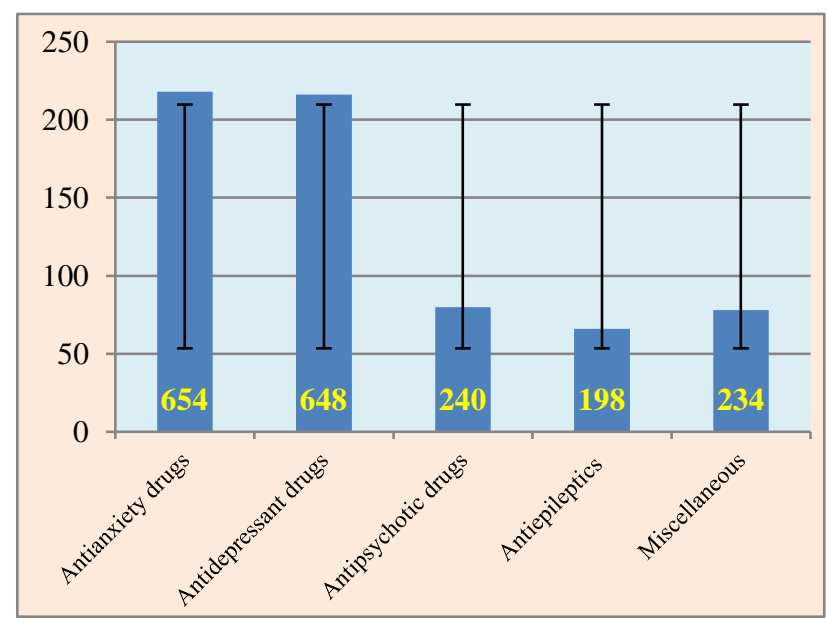

Figure 2: Prescribed drug groups.

Out of 654 antianxiety drugs, $558 \quad(85.32 \%)$ benzodiazepines were prescribed, that includes 270 (41.28\%) clonazepam, 111 (16.97\%) diazepam, 93 (14.22\%) alprazolam, $60(9.17 \%)$ lorazepam, 21 (3.21\%) etizolam and $3(0.46 \%)$ chlordiazeperoxide respectively. 96 (14.68\%) prescriptions included Propanolol amongst antianxiety drugs (Table 2).

Table 2: Anti-anxiety drugs prescribed.

\begin{tabular}{|lll|}
\hline Type of Drug & Name & Number (\%) \\
\hline \multirow{3}{*}{ Benzodiazepines } & Clonazepam & $270(41.28)$ \\
\cline { 2 - 3 } & Diazepam & $111(16.97)$ \\
\cline { 2 - 3 } & Alprazolam & $93(14.22)$ \\
\cline { 2 - 3 } & Lorazepam & $60(9.17)$ \\
\cline { 2 - 3 } & Etizolam & $21(3.21)$ \\
\cline { 2 - 3 }$\beta$-Blockers & Chlordiazepoxide & $3(0.46)$ \\
\hline & Propranolol & $96(14.68)$ \\
\hline
\end{tabular}

$552(91.54 \%)$ patients were given monotherapy and 51 $(8.46 \%)$ patients received polytherapy of anxiolytics (Figure 3).

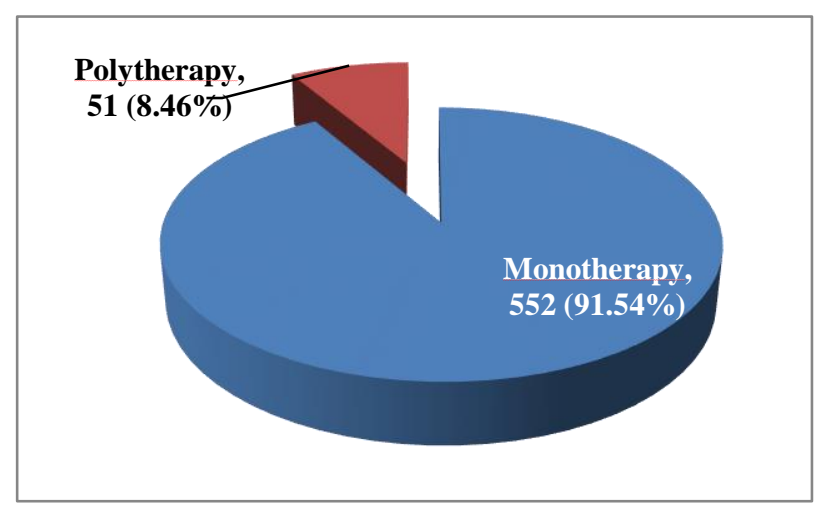

Figure 3: Distribution of prescription of anxiolytics.

All (100\%) anxiolytics were prescribed orally. A total of 30 fixed dose combinations (FDCs) of anxiolytics were prescribed. The numbers of anxiolytics prescribed per prescription were 1.085 . The anxiolytics prescribed from National Essential Medicine List 2015 were 555 $(84.86 \%)$. The percentage of anxiolytics with brand names was $618(94.5 \%)$ (Table 3).

Table 3: WHO drug use indicators.

\begin{tabular}{|ll|}
\hline Parameter & Number (\%) \\
\hline Anxiolytics per prescription & 1.085 \\
\hline Anxiolytics from NEML 2015 & $555(84.86 \%)$ \\
\hline Anxiolytics with brand names & $618(94.5 \%)$ \\
\hline Oral drugs & $100 \%$ \\
\hline FDCs of anxiolytics & $30(4.58 \%)$ \\
\hline
\end{tabular}

\section{DISCUSSION}

A total of 603 prescriptions of patients diagnosed with anxiety disorder were collected from Psychiatry Outpatients Department. The patients had a mean age of $35.46 \pm 0.88$ years; this is in collaboration with previous studies, where high prevalence was seen in 31-40 years age group. ${ }^{7,8}$ In the present study males were the frequent sufferers of psychiatric disorders. This finding was in contrast to the earleir study, which showed that females were most commonly suffering from anxiety. ${ }^{9}$ According to profession, housewives were most affected by anxiety disorders; this was in collaboration with previous study. ${ }^{10}$ A positive history of addiction was found in $42.78 \%$ patients, which was similar to the previous study that revealed history of substance abuse associated with psychiatric disorders. $^{7}$ The disease pattern of psychiatric illness was also studied which revealed that anxiety disorders were the most prevalent psychiatric illness. A meta-analysis of 13 psychiatric epidemiological studies by Reddy and Chandrashekhara et al, has yielded the similar results. ${ }^{11}$ In present study antianxiety drugs were the most frequently prescribed psychotropic drugs 
followed by antidepressants, similar observations were seen in previous study. ${ }^{12}$ Benzodiazepines were the most commonly prescribed anxiolytic in our study; this finding is similar to previous studies. ${ }^{13,14}$ The most commonly prescribed Benzodiazepine was clonazepam followed by diazepam, similar results were observed in previous studies. ${ }^{10,15}$ Short acting benzodiazepines were more frequently prescribed as it is seen that continuous and prolonged use of longer acting Benzodiazepines results in dependence and may have withdrawal symptoms when the dosage of these drugs are reduced or treatment is stopped. $^{16}$ Besides benozdiazepines, propanolol (beta blocker) was also used as an anxiolytic, this is in accordance with previous studies. ${ }^{10,17}$

At least one anxiolytic drug was prescribed in every patient. Monotherapy of anxiolytics was prescribed in majority $(91.54 \%)$ of the patients, which is similar to previous study, where $94 \%$ patients were prescribed anxiolytics as monotherapy. ${ }^{10}$ The average number of drugs prescribed per prescription is an important indicator of rational prescribing. Anxiolytics prescribed per prescription were 1.085 in our study; this is in contrast to previous studies, where 1.7-3.3 anxiolytics per prescription were prescribed. ${ }^{15-18}$ Hence the rational use of anxiolytics was followed. Clinicians may use polypharmacy in patients as combination therapy for symptom relief, while using lower doses of drugs with differing side-effects profiles. Polypharmacy increases the possibility of cumulative toxicity and increased vulnerability to adverse events as well as poor adherence. ${ }^{19}$ In our study majority of anxiolytics were prescribed from National List of Essential Medicines (NEML) 2015, this was in accordance with previous studies by Ghosh $\mathrm{S}$ and Jena $\mathrm{M}$, et al. ${ }^{10,15}$ Prescribing drugs from NEML is a very important indicator of rational prescribing which was followed in majority of the prescriptions. All drugs were prescribed orally $(100 \%)$ indicating that all patients were having mild to moderate anxiety, this was in accordance with previous study. ${ }^{17}$ Most of the drugs were prescribed by brand names $(94.5 \%)$, similar trend was seen in previous study by Sahana et al, and in contrast with the study by Shankar and Roy. ${ }^{20,21}$ This is not in accordance with the WHO guidelines as rational prescribing requires generic prescription.

\section{CONCLUSION}

Studying and analyzing the prescription patterns help the physicians in understanding how the available drugs can be rationally. If necessary, modifications in prescribing patterns so as to make medical care rational, and our study was a step in that direction. Most of the prescriptions were rational but there is a need to encourage prescribing by generic names so that more cost-effective and rational treatment can be provided to the patients.

Funding: No funding sources Conflict of interest: None declared
Ethical approval: The study was approved by the Institutional Ethics Committee

\section{REFERENCES}

1. Trivedi JK, Gupta PK. An overview of Indian research in anxiety disorders. Indian J Psychiatry. 2010;52(1):S210-8.

2. Solanki G. Anti-Anxiety Drugs. An Overview. International Journal of Biomedical Research. 2013 Feb 1;4(1):1-4.

3. Bandelow B, Wedekind D, Leon T. Pregabalin for the treatment of generalized anxiety disorder: a novel pharmacologic intervention. Expert Rev Neurother. 2007;7(7):769-81.

4. Clark RH, Bloom BT, Spitzer AR, Gerstmann DR. Reported Medication Use in the Neonatal Intensive Care Unit: Data from a Large National Data Set. Paediatrics. 2006;117:1979-7.

5. ESEMeD/MHEDEA 2000 investigators: Prevalence of mental disorders in Europe: results from the European Study of the Epidemiology of Mental disorders (ESEMeD) project. Acta Psychiatrica Scandinavica. 2004;109(420):21-7.

6. Davidson JR, Feltner DE, Dugar A. Management of generalized anxiety disorder in primary care: identifying the challenges and unmet needs. Prim Care Companion J Clin Psychiatry. 2010;12(2).

7. Lesen E, Anderrson K, Petzoid M, Carlsten A. Socioeconomic determinants of Psychotropic drug utilization among elderly: a national population based cross sectional study. BMC Public Health. 2010;10(118):1-9.

8. Rao TSS, Darshan MS, Tandon A, Raman R, Karthik KN, Saraswathi N, et al. Suttur study: An epidemiological study of psychiatric disorders in south Indian rural population. I $\mathbf{J}$ of Psy. 2014;56(3):238-5.

9. Chakos M, Lieberman J, Hoffman E, Bradford D, Sheitman B. Effectiveness of second-generation antipsychotics in patients with treatment-resistant schizophrenia: a review and meta-analysis of randomized trials. Am J Psychiatry. 2001;158(4):518-6.

10. Ghosh S, Bhattacharyya S, Bhattacharya A. Medications for anxiety: A drug utilization study in psychiatry outpatients from a tertiary care centre of Eastern India. Journal of Drug Delivery and Therapeutics. 2013;3(4):79-4.

11. Chandrashekhar CR, Reddy MV. Prevalence of mental and behavioural disorders in India: A metaanalysis. Indian J Psychiatry. 1998;40:149-7.

12. Dutta S, Beg MA, Kaul V, Dutta SH, Dhasmana DC. Psychotropic drug utilization study in psychiatric OPD of a tertiary care teaching hospital in Dehradun, Uttarakhand. J Adv Res Biol Sci. 2013;5(4):386-1.

13. Jacobson GA, Friesen WT, Peterson GM, Rumble RH, Polack AE. Psychoactive drug prescribing in the Tasmanian community. Med J Aust. 1992;157(1):204. 
14. Banerjee R, Sathian B, Banerjee KS, Saha A. Medications for Anxiety: A Drug utilization study in Psychiatry inpatients from a Tertiary Care Centre of Western Nepal. Nepal J of Epi. 2011;1(4):119-5.

15. Jena M, Mishra S, Mishra SN, Mishra SS. Psychotropic drugs: Prescribing pattern in Psychiatry Outpatient Department of a tertiary care teaching hospital. Int J Pharm. 2014;4(4):204-8.

16. Lader MH, Bond AJ, James DC. Clinical comparison of anxiolytic drug therapy. Psychol Med. 1974;4:3817.

17. Dutta SB, Beg MA, Sindhu S, Singh NK. Role of pharmaco-epidemiology in psychopharmacology: a study in psychiatric out-patient department of a tertiary care teaching hospital at Dehradun, Uttarakhand. Int J Basic Clin Pharmacol. 2014;3(4):637-3.

18. Rittmannsberger $\mathrm{H}$, Meise $\mathrm{U}$, Schauflinger $\mathrm{K}$, Horvath E, Donat H, Hinterhuber H. Polypharmacy in psychiatric treatment. Patterns of psychotropic drug use in Austrian psychiatric clinics. Eur Psychiatry. 1999;14(1):33-40.
19. Trumic E, Pranjic N, Begic L, Becic F, Asceric M. Idiosyncratic adverse reactions of most frequent drug combinations long term use among hospitalized patients with polypharmacy. Med Arh. 2012;66(4):243-8.

20. Sahana DA, Keshava P, Rajeshwari S, Ullal SD, Rathnakar UP, Jaykumar JS. Pattern of psychotropic drug usage in psychiatric illnesses among elderly. $\mathbf{J}$ Med Dev Ctries. 2010;2(1):3-10.

21. Shankar PR, Roy S. Patterns of prescription and drug use in a psychiatry out-patient department in a teaching hospital in Western Nepal. Internet $\mathbf{J}$ Pharmacol. 2002;1(2):1-6.

Cite this article as: Dutta SB, Beg MA, Bawa S, Kaur A, Vishal S, Singh NK. Study on drug usage pattern of anxiolytics in psychiatric department in a tertiary care teaching hospital at Dehradun, Uttarakhand, India. Int J Basic Clin Pharmacol 2017;6:1661-5. 